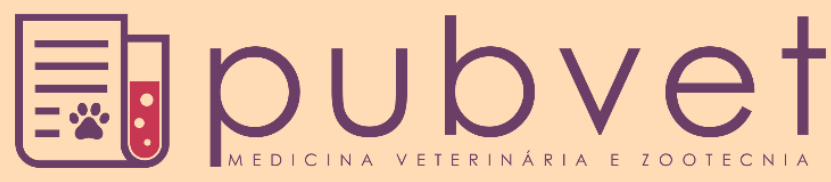

https://doi.org/10.31533/pubvet.v15n04a791.1-5

\title{
$O$ excesso de carboidrato na dieta do gato doméstico
}

\author{
Tarcísio Alves Barreto Filho ${ }^{1 *} \mathbb{9}$, Anny Gabriele Oliveira Fonsêca ${ }^{2}$, Fernanda Ingrid Dantas ${ }^{2} \mathbb{9}$, \\ João Antônio da Silva ${ }^{2}$, Melina Botêlho Garcia ${ }^{2}$, Mariana Silva Bochnakian², Jaqueline da Silva \\ Galvíncio $^{4}$
}

${ }^{1}$ Médico Veterinário, Mestrando em Biotecnologia da Saúde, Universidade Potiguar (UnP), Natal - RN, Brasil.

${ }^{2}$ Discentes do curso de Medicina Veterinária, Universidade Potiguar (UnP), Natal - RN, Brasil.

${ }^{3}$ Médica veterinária pós-graduanda em Clínica Médica de Felinos, Equalis, Natal-RN, Brasil.

${ }^{4}$ Médica Veterinária, Pós-graduanda em Medicina Intensiva de Pequenos Animais, Equalis, Natal - RN, Brasil.

*Autor para correspondência, E-mail: tarcisioabfilho@yahoo.com.br

Resumo. O excesso de carboidratos consumido em dietas industriais por felinos domésticos pode causar diversas patologias e malefícios para o bem-estar animal. O gato é classificado como carnívoro estrito e por isso possui singularidade em sua alimentação. Mesmo com o crescente investimento das empresas fabricantes de rações, não existem informações científicas significantes acerca da nutrição e biodisponibilidade de nutrientes para felinos. Muitas marcas de rações utilizam mais da metade de carboidratos na matéria bruta de suas rações, entretanto, os gatos não possuem necessidade nutricional dos mesmos, afetando sua digestibilidade e formando fatores antinutricionais. Desse modo, pode-se afirmar que a nutrição dos felinos precisa ser mais amplamente debatida cientificamente e é necessário que as peculiaridades alimentares de proteínas, lipídeos, vitaminas, além do maior conhecimento do seu comportamento herdado de felinos silvestres desses animais sejam respeitadas para a maior promoção de saúde e qualidade de vida.

Palavras chave: Exigências nutricionais, gato, ração

\section{Excess carbohydrate in the domestic cat's diet}

\begin{abstract}
Excess carbohydrates consumed in industrial diets by domestic cats can cause various pathologies and harms to the welfare of the animal. The cat is classified as a strict carnivore and therefore has uniqueness in its food. Even with the increasing investment of feed manufacturers, there is no significant scientific information on feline nutrition and nutrient bioavailability. Many brands of feed use more than half of the carbohydrates in the raw material of their feed, however, cats do not have their nutritional needs, affecting their digestibility and forming anti-nutritional factors. Thus, it can be stated that feline nutrition needs to be more scientifically debated and it is necessary that the dietary peculiarities of proteins, lipids, vitamins, as well as a better knowledge of their inherited behavior of wild felines of these animals, must be respected for the most part. health promotion and quality of life.
\end{abstract}

Keywords: Nutritional requirements, cat, feed

\section{Exceso de carbohidratos en la dieta del gato doméstico}

Resumen. El exceso de carbohidratos consumidos en las dietas industriales por los gatos domésticos puede causar diversas patologías y daños al bienestar del animal. El gato se clasifica como carnívoro estricto y, por lo tanto, tiene singularidad en su alimentación. Incluso con la creciente inversión de los fabricantes de piensos, no hay información científica significativa sobre nutrición felina y biodisponibilidad de nutrientes. Muchas 
marcas de alimento usan más de la mitad de los carbohidratos en la materia prima de su alimento, sin embargo, los gatos no tienen dichas necesidades nutricionales de estos, lo que afecta su digestibilidad y forma factores antinutricionales. Por lo tanto, se puede afirmar que la nutrición felina necesita ser más debatida científicamente y es necesario que las peculiaridades dietéticas de proteínas, lípidos, vitaminas, así como un mejor conocimiento de su comportamiento heredado de felinos salvajes de estos animales se respeten en su mayor parte para promover salud y calidad de vida.

Palabras clave: Requerimientos nutricionales, gato, alimento

\section{Introdução}

O gato é eleito como pet em diversos países devido ao seu comportamento e fácil adaptação ao estilo de vida de seus tutores (Driscoll et al., 2007). Esse animal possui maior necessidade de proteína quando comparado aos demais animais domésticos, no entanto a razão ainda é desconhecida (Zaghini \& Biagi, 2005). Esses animais possuem necessidades de proteína mais elevados do que outros animais domésticos, mas a razão para esta diferença ainda não é completamente compreendida (Little, 2016).

Por ser um animal carnívoro estrito, possui diferenças anatômicas e fisiológicas singulares, como dentição específica para rasgar e ausência de amilase (NRC, 2006). Além de necessidades alimentares específicas. Muito é investido no setor pet, inclusive em sofisticação de rações, no entanto, segundo Bontempo (2005), mesmo com o desenvolvimento industrial na produção de dietas para felinos, ainda não possuímos muitas informações sobre todos os ingredientes empregados nas rações, assim como a biodisponibilidade desses nutrientes (Steiff \& Bauer, 2001).

O objetivo desse trabalho é expor as peculiaridades nutricionais do gato doméstico por meio de uma revisão de literatura, dada a importância do tema para a saúde felina, além de enfatizar os prejuízos do excesso de carboidratos em sua dieta.

\section{Especificidades nutricionais do gato}

Os gatos domésticos mantem o comportamento e a capacidade de caçar conservada de forma eficaz (Bradshaw et al., 1996). Segundo Lipinski et al. (2008), o felino, mesmo com tantos anos de domesticação, ainda assemelha-se aos antigos felinos silvestres em seu genoma, morfologia e comportamento. Mesmo com a formação de diversas raças há décadas, é hipotético dizer que isso resultou em mudanças importantes tanto em sua fisiologia quanto ao seu metabolismo.

Cada vez mais a indústria pet investe em sofisticação e expansão de dietas comerciais prontas para o consumo de cães e gatos, no entanto, as informações cientificas relacionadas a nutrição e biodisponibilidade dos nutrientes empregados de pequenos animais ainda é insuficiente (Plantinga et al., 2011), fazendo, na maior parte das vezes, com que as fórmulas desses alimentos sejam baseadas nos nutrientes brutos, sem ao menos possuírem tabelas de composição nas rações de cães e gatos com estimativa de nutrientes digestíveis (Bontempo, 2005).

Os felinos possuem diferenças anatômicas e fisiológicas que demonstram sua classificação como carnívoro. Possuem a mesma quantidade de dentes dos cães, no entanto, seus dentes pré-molares e molares possuem ranhuras em sua porção exterior, sendo que essa dentição é específica para rasgar carne, além da falta de amilase (NRC, 2006). Os gatos também possuem menor capacidade estomacal quando comparado com os cachorros, devido ao habito de consumir pequenas presas durante o dia. Além disso, possuem o intestino menor quando comparado a onívoros. O intestino diminuído do felino implica em um tempo de digestão e absorção reduzidos (Little, 2016).

Frequentemente esses animais possuem favoritismo por alimentos úmidos em comparação com os secos, no entanto, se forem alimentados apenas com ração seca por demasiado tempo podem desenvolver paladar apenas para alimentação seca (MacDonald et al., 1984).

\section{Proteína}

A proteína é indispensável para os gatos, eles possuem necessidades de proteína mais elevadas do que outros animais domésticos, no entanto, o motivo não é completamente conhecido (NRC, 2006). 
Além disso, os gatos também possuem altas exigências de nitrogênio em seu alimento. Uma possível razão para a elevada necessidade de proteína é a cerca das enzimas hepáticas que estão envolvidas no catabolismo de aminoácidos (MacDonald et al., 1984). A medida que a maioria dos animais conseguem reduzir a atividade destas enzimas, sendo alimentados com dietas de baixo quantidade de proteína, os gatos são incapazes de adaptar-se ao catabolismo de proteínas e a atividade do ciclo da ureia para dietas deficientes em proteínas (Rogers et al., 1977).

De acordo com Park et al. (1991), os felinos não conseguem sintetizar a taurina através da metionina e cisteína como a maioria dos mamíferos, pois possuem baixa atividade dessas enzimas, então, esses animais adquirem a taurina através do consumo de tecidos animais. Além disso, Spitze et al. (2003) cita que caso os níveis de taurina não sejam suficientes no organismo, os gatos podem desenvolver patologias como insuficiência reprodutiva, cardiomiopatia dilatada e degeneração central da retina. Além da taurina, os gatos domésticos não sintetizam arginina de glutamato e glutamina (Morris, 1985).

\section{Lipídeos}

Segundo Gurr et al. (2002), os triglicerídeos são as principais gorduras consumidas pelos gatos, através deles os ácidos graxos são absorvidos, os quais são fontes energéticas para os felinos. A necessidade de ácidos de cadeia longa poli-insaturados não é informada com exatidão, no entanto, MacDonald et al. (1984) afirma que os felinos sintetizam o araquidonato de linoleato com capacidade restrita causada pela pequena atividade da enzima desaturase encontrada no fígado. Com isso, foi designada a utilização de gordura de origem animal para obtenção do araquidonato, que é um precursor da síntese dos eicosanoides muito presente nas membranas celulares (Rivers et al., 1975).

A gordura é o maior contribuinte em energia na dieta dos carnívoros além de ser um fator influenciador na palatabilidade e aceitação dos alimentos pelos animais (MacDonald et al., 1984).

\section{Vitaminas}

Os gatos não possuem a enzima dioxigenase, ao contrário de grande parte dos animais, responsável pela conversão de carotenoides para a forma ativa, vitamina A (Schweigert et al., 2002). A vitamina A está presente em tecidos animais, especificamente nas vísceras. A vitamina A pode ser tóxica em grande quantidade em diversos animais, entretanto os felinos conseguem tolerar níveis maiores dessa vitamina, geralmente sem a consequência de hipervitaminose A (Raila et al., 2001). O felino consegue armazenar a vitamina A tanto no fígado quanto nos rins, a maior excreção de vitamina A pela urina é um mecanismo que tende a diminuir a toxidade dessa vitamina (Little, 2016).

Além da vitamina D, a vitamina B3 são essenciais para os felinos. A niacina pode ser sintetizada por via endógena através do triptofano (Morris, 1985). A tiamina participa da formação do pirofosfato, coenzima tiamina que atua como coenziama na descarboxilação. Em comparação ao cão, o gato necessita de cerca de 4 vezes mais devido ao seu maior catabolismo e gliconeogênese (Zaghini \& Biagi, 2005).

\section{Carboidratos}

Segundo Little (2016), os gatos não possuem exigência nutricional de carboidratos em suas dietas. Os felinos obtêm a maior parcela da sua necessidade energética através da proteína. Eles possuem diversas peculiaridades fisiológicas que provam a baixa necessidade de carboidrato em suas dietas, como por exemplo, a ausência de amilase salivar e baixa amilase intestinal e pancreática, assim como a baixa atividade de dissacarídeos no intestino delgado que comprometem a quebra dos carboidratos (Springer et al., 2009; Stipanuk \& Caudill, 2018). Uma maior ingestão de carboidratos também provoca a acidificação fecal nesses animais, decorrente da fermentação acentuada de bactérias no intestino delgado que eleva a produção de ácidos orgânicos (Swanson, 2007).

A ração extrusada para animais, possui o amido como maior constituinte de energia em sua formação. Em muitas rações, esse carboidrato pode representar até 55\% da matéria seca do alimento, no entanto, apenas uma parcela ingerida possui resistência a hidrolise nos monogástricos devido as interações com as proteínas, causando com isso uma série de fatores antinutricionais (Carciofi, 2008). 
Os carboidratos em excesso na dieta dos felinos contribuem para diversas doenças. A obesidade é uma patologia frequente em felinos e uma das causas do aparecimento dessa doença é o excesso de carboidratos simples utilizados em rações, devido a incapacidade do felino de metabolizar grandes quantidades desse nutriente (Silva et al., 2019).

\section{Considerações Finais}

Os felinos possuem necessidades nutricionais especificas por serem carnívoros e essas necessidades precisam ser atendidas. $\mathrm{O}$ excesso de carboidrato encontrado em diversas rações secas contraria as exigências dietéticas da espécie, visto que os gatos domésticos não necessitam de carboidratos em sua alimentação, acarretando patologias como a obesidade. Com isso, é necessário maiores pesquisas pela indústria para a fabricação de alimentos que atendam a demanda nutricional dos felinos. Assim, uma dieta adequada as peculiaridades dos gatos domésticos refletem em saúde e mais qualidade de vida.

\section{Referências}

Bontempo, V. (2005). Nutrition and Health of Dogs and Cats: Evolution of Petfood. Veterinary Research Communications, 29(S2), 45-50. https://doi.org/10.1007/s11259-005-0010-8

Bradshaw, J. W. S., Goodwin, D., Legrand-Defrétin, V., \& Nott, H. M. R. (1996). Food selection by the domestic cat, an obligate carnivore. Comparative Biochemistry and Physiology Part A: Physiology, 114(3), 205-209. https://doi.org/10.1016/0300-9629(95)02133-7

Carciofi, A. C. (2008). Fontes de proteína e carboidratos para cães e gatos. Revista Brasileira de Zootecnia, 37(spe), 28-41. https://doi.org/10.1590/S1516-35982008001300005

Driscoll, C. A., Menotti-Raymond, M., Roca, A. L., Hupe, K., Johnson, W. E., Geffen, E., Harley, E. H., Delibes, M., Pontier, D., Kitchener, A. C., Yamaguchi, N., O’Brien, S. J., \& Macdonald, D. W. (2007). The Near Eastern Origin of Cat Domestication. Science, 317(5837), 519-523. https://doi.org/10.1126/science.1139518

Gurr, M. I., Harwood, J. L., \& Frayn, K. N. (2002). Lipid biochemistry (5 ed. Blac, Vol. 409). Springer.

Lipinski, M. J., Froenicke, L., Baysac, K. C., Billings, N. C., Leutenegger, C. M., Levy, A. M., Longeri, M., Niini, T., Ozpinar, H., Slater, M. R., Pedersen, N. C., \& Lyons, L. A. (2008). The ascent of cat breeds: Genetic evaluations of breeds and worldwide random-bred populations. Genomics, 91(1), 12-21. https://doi.org/10.1016/j.ygeno.2007.10.009

Little, S. E. (2016). O gato: medicina interna. In Rio de Janeiro: Roca (pp. 978-989).

MacDonald, M. L., Rogers, Q. R., \& Morris, J. G. (1984). Nutrition of the Domestic Cat, a Mammalian Carnivore. Annual Review of Nutrition, 4(1), 521-562. https://doi.org/10.1146/annurev.nu.04.070184.002513

Morris, J. G. (1985). Nutritional and Metabolic Responses to Arginine Deficiency in Carnivores. The Journal of Nutrition, 115(4), 524-531. https://doi.org/10.1093/jn/115.4.524

NRC. (2006). Nutrient Requirements of Dogs and Cats. National Academies Press. https://books.google.com.br/books?id=aqeCwxbRWvsC

Park, T., Jerkins, A. A., Steele, R. D., Rogers, Q. R., \& Morris, J. G. (1991). Effect of Dietary Protein and Taurine on Enzyme Activities Involved in Cysteine Metabolism in Cat Tissues. The Journal of Nutrition, 121(suppl_11), S181-S182. https://doi.org/10.1093/jn/121.suppl_11.S181

Plantinga, E. A., Bosch, G., \& Hendriks, W. H. (2011). Estimation of the dietary nutrient profile of freeroaming feral cats: possible implications for nutrition of domestic cats. British Journal of Nutrition, 106(S1), S35-S48. https://doi.org/10.1017/S0007114511002285

Raila, J., Mathews, U., \& Schweigert, F. J. (2001). Plasma transport and tissue distribution of $\beta$-carotene, vitamin A and retinol-binding protein in domestic cats. Comparative Biochemistry and Physiology Part A: Molecular \& Integrative Physiology, 130(4), 849-856. https://doi.org/10.1016/S10956433(01)00443-3

Rivers, J. P. W., Sinclair, A. J., \& Crawford, M. A. (1975). Inability of the cat to desaturate essential fatty acids. Nature, 258(5531), 171-173. https://doi.org/10.1038/258171a0

Rogers, Q. R., Morris, J. G., \& Freeland, R. A. (1977). Lack of Hepatic Enzymatic Adaptation to Low and High Levels of Dietary Protein in the Adult Cat. Enzyme, 22(5), 348-356. 
https://doi.org/10.1159/000458816

Schweigert, F. J., Raila, J., Wichert, B., \& Kienzle, E. (2002). Cats Absorb $\beta$-Carotene, but It Is Not Converted to Vitamin A. The Journal of Nutrition, 132(6), 1610S-1612S. https://doi.org/10.1093/jn/132.6.1610S Silva

Spitze, A. R., Wong, D. L., Rogers, Q. R., \& Fascetti, A. J. (2003). Taurine concentrations in animal feed ingredients; cooking influences taurine content. Journal of Animal Physiology and Animal Nutrition, 87(7-8), 251-262. https://doi.org/10.1046/j.1439-0396.2003.00434.x

Springer, N., Lindbloom-Hawley, S., \& Schermerhorn, T. (2009). Tissue expression of ketohexokinase in cats. Research in Veterinary Science, 87(1), 115-117. https://doi.org/10.1016/j.rvsc.2008.11.004

Steiff, E. L., \& Bauer, J. E. (2001). Nutritional adequacy of diets formulated for companion animals. Journal of the American Veterinary Medical Association, 219(5), 601-604. https://doi.org/10.2460/javma.2001.219.601

Stipanuk, M. H., \& Caudill, M. A. (2018). Biochemical, Physiological, and Molecular Aspects of Human Nutrition - E-Book. Elsevier Health Sciences. https://books.google.com.br/books?id=fEpVDwAAQBAJ

Swanson, K. S. (2007). Using molecular techniques to study canine and feline gut microbial ecology. Compendium: Continuing Education For Veterinarians, 29((2 SUPPL. A)), 34-36.

Zaghini, G., \& Biagi, G. (2005). Peculiaridades nutricionais e dieta palatabilidade do gato. VeterinaryResesearch Communis, 29(2), 1-5.

Histórico do artigo:

Recebido: 8 de setembro de 2020.

Aprovado: 15 de outubro de 2020 .

Disponível online: 9 de dezembro de 2020.
Licenciamento: Este artigo é publicado na modalidade Acesso Aberto sob a licença Creative Commons Atribuição 4.0 (CC-BY 4.0), a qual permite uso irrestrito, distribuição, reprodução em qualquer meio, desde que o autor e a fonte sejam devidamente creditados. 